\section{$014-015$ \\ Noticias y comentarios \\ PH47 - Febrero 2004}

europeas y universales. La Unesco, el Icom e Icomos son referentes imprescindibles.

Unánimemente se ha indicado que la protección, la conservación, la restauración son tareas de equipos multidisciplinares de especialistas que deben actuar perfectamente coordinados.

Importante es apuntar que constantemente se ha proclamado que la protección del patrimonio es tarea de todos los ciudadanos, resaltando la importancia de educar en el conocimiento y el respeto del patrimonio y -muy singularmente- el papel de las asociaciones de defensa del patrimonio (se señaló el gran potencial que suponen los 2.300 poseedores de la tarjeta Mecenas Amigos del Patrimonio de la Fundación del Patrimonio Histórico de Castilla y León). Las asociaciones tienen que abrirse a la sociedad y ellas y las administraciones deben precisar cauces de diálogo. Este último punto se ha relacionado directamente con la reflexión más repetida: el modelo a seguir por quienes estamos comprometidos con la defensa del legado de la memoria patrimonial es el del movimiento en defensa del medio ambiente, de la naturaleza, del patrimonio ambiental, hay que buscar la sensibilización general y hay que partir de la educación y la formación.
Como coordinador del Simposio debo apuntar dos acuerdos obvios más, que quizás no se concretaron en el Salón de sesiones, pero sí en las tertulias siguientes. Preciso es que las distintas leyes se cumplan, y asi se ha insinuado que el Estado asuma todas las competencias que la Constitución, la Ley de patrimonio del 85 y distintas sentencias judiciales han definido; quienes incumplen con las numerosas leyes que defienden el patrimonio deben terminar ante un juez y cumplir las sentencias que sobre ellos recaigan. Las actuaciones sobre edificios monumentales deben cumplir con la legislación española y con los acuerdos internacionales asumidos por España, deben ser acometidas por equipos interdisciplinares y en ellas debe huirse de plantear actuaciones de diseño y relumbrón sobre conjuntos patrimoniales pretextando su restauración. El Simposio escuchó atónito como Pedro Navascués advertía de una posible declaración de BIC del "nuevo teatro de Sagunto" que sortearía la sentencia judicial y legalizaría a posteriori el expolio cometido.

José Luis Gutiérrez Robledo

Universidad Complutense de Madrid

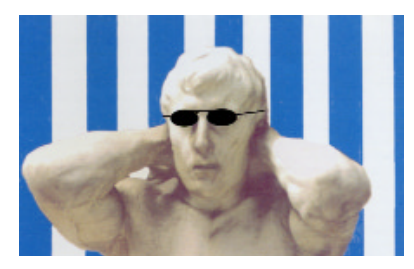

\title{
El III Congreso de Historia Antigua de Málaga recupera la memoria de lo clásico
}

Entre los días 29 y 31 de octubre de 2003 se celebró el III Congreso de Historia Antigua de Málaga, con el tema monográfico La Tradición Clásica en Málaga (XVI-XXI), organizado por el Grupo de Estudios Historiográficos y el Área de Historia Antigua de la Facultad de Filosofía y Letras de Málaga.

Los dos congresos anteriores se celebraron en 1994 y 1998, dando lugar a dos publicaciones, ambas dedicadas a la historia antigua de Málaga y provincia; la primera planteaba un estado de la cuestión del conjunto de los problemas suscitados entre el siglo VIII a. C. y los comienzos del VIII d. C., y el segundo se centró en el tema del Comercio y Comerciantes en la Historia Antigua de Málaga, en este mismo periodo. Dada la existencia de ambas publicaciones que ofrecen una puesta al día suficientemente sólida sobre todo ello, se pensó en esta ocasión plantear un tema diferente, el de la tradición clásica en Málaga y provincia desde la conquista cristiana de la ciudad a finales del s. XV hasta la actualidad.

El punto de partida es, entonces, el hecho innegable de la presencia del referente del mundo grecorromano en las elaboraciones culturales europeas desde el Renacimiento, sólo paralelizable a lo que supone en el campo más ligado a lo religioso la judeocristiana. Se trataba, entonces, de partir de este hecho y de asumir la perspectiva de que se trata de una zona que, con independencia de presentar una gran riqueza arqueológica desde los fenicios hasta los bizantinos y visigodos, si es significativa no es por su carácter de gran foco cultural, sino precisamente por el hecho contrario: por ser una más de las ciudades andaluzas, españolas 0 europeas en el uso de esa tradición clásica a lo largo del tiempo. Interesaba, en consecuencia, más que la eventual búsqueda de elementos destacados o excepcionales, entender las múltiples presencias, las múltiples actualidades que había supuesto la memoria de lo clásico en este espacio a lo largo del tiempo y hasta el presente.

Se buscó posibilitar un encuentro científico que presentase un panorama amplio de estos usos en todos los campos y momentos del periodo en estudio, siempre en la perspectiva de propiciar debates transversales y multidisciplinares que desbordaran los marcos académicos convencionales en los que se fragmenta un tema tan complejo y multiforme, con la intención de llegar también hasta un presente en el que cabe volver a preguntarse, como en tantos momentos anteriores, sobre qué uso cabe darle a una memoria así de rica y de omnipresente.

Tras una presentación de los objetivos del Congreso a cargo de su director (La Antigüedad viva. 
Viva la Antigüedad. Razones para un Congreso), se desarrolló éste en cuatro secciones. La primera, con ponencias a cargo del Grupo de Estudios Historiográficos y de M. Olmedo Checa, se dedicó a Historia e Instituciones, con especial incidencia en el tratamiento de la Antigüedad en historiadores, anticuarios, eruditos e instituciones como las Academias.

La segunda se dedicó a Patrimonio y Artes Plásticas. Una primera ponencia, a cargo de la Dra. M. T. Sauret Guerrero abarcó el primer aspecto, La presencia de lo Clásico en el Arte en Málaga. La Dra. M. C. Rodriguez Oliva y S. Fernández Cacho, del Instituto Andaluz de Patrimonio Histórico (IAPH), presentaron en dos intervenciones realizadas bajo el epígrafe El Patrimonio Histórico Antiguo de Málaga en el Sistema de Información del Patrimonio Cultural del IAPH los aspectos patrimoniales desde la perspectiva del trabajo de esta institución.

La tercera, dedicada a la Literatura, presentó también una doble dimensión, en este caso, una ponencia dedicada a los Escritores humanistas de Málaga a cargo del Dr. F. Talavera Esteso, y otra sobre Antigüedad y Clasicismo en la literatura malagueña, a cargo de los Dres. A. Quiles Faz, A. Gómez Yebra y E. Garcés.

La cuarta sección, por último, se centró en La Creación contemporánea y el Mundo Antiguo, con una ponencia a cargo del Dr. E. Baena Peña, titulada La creación contemporánea: mitos y símbolos del clasicismo.

Varios aspectos destacan en el conjunto de las ponencias, comunicaciones y mesas redondas. En primer lugar, la necesidad de reforzar los es- tudios multidisciplinares en el contexto de reflexiones que al tratar los hechos culturales no pierdan de vista los diferentes contextos históricos específicos en los que se producen; no sólo es el mismo público el que recibe en un momento dado las producciones literarias o contempla o contrata las artísticas, es que la formación y el ambiente de los diferentes autores bebe de fuentes similares.

En segundo lugar, hay que incidir en que los estudios locales no deben ser confundidos con estudios localistas; como ningún otro, el uso de ese patrimonio común, antes europeo y ahora universal, que es la tradición clásica, exige miradas globales a las corrientes y procesos más generales en los que está inmersa.

En tercer lugar, destaca el interés por el presente de lo Clásico, sobre su uso, por ejemplo, en el arte tras el final del postmodernismo artístico o en la publicidad y la decoración. Pero en particular se incidió en el interés por el Patrimonio y sus usos; es en este sentido en el que resultó particularmente destacable la presencia del IAPH, en particular en su condición de foco de información de primer orden. La preocupación por el estado real del patrimonio andaluz, especialmente, del arqueológico, y la desproporción entre su abundancia y los medios de que se dispone para su protección, conservación y disfrute fue el factor más recalcado en este terreno.

Fernando Wulff

Área de Historia Antigua de la Universidad de Málaga

Director del Congreso

\section{Asociaciones de defensa del patrimonio promueven el Camino del Cid como itinerario cultural}

La XXV Reunión de Asociaciones de Defensa del Patrimonio Cultural y su entorno, convocada por Hispania Nostra, ha contado este año con la asistencia de más de cincuenta asociaciones procedentes de toda la geografía española. Celebrada en Burgos los días 14, 15 y 16 de noviembre de 2003, bajo los auspicios del Ayuntamiento y de la Diputación Provincial de Burgos, y con el patrocinio de la Caja de Burgos, la Caja del Círculo y la Cámara Oficial de Comercio e Industria de Burgos, la Reunión ha deliberado acerca de la protección y promoción del denominado Camino del Cid como itinerario cultural, y como resultado de sus sesiones de trabajo ha aprobado las siguientes conclusiones:

1. La idea de proteger y promover el Camino del Cid como itinerario cultural ha de basarse ante todo en el Cantar de Mío Cid como obra litera- ria. La motivación cultural para la creación de este itinerario radica en la potencia evocadora del Poema, que debe mantenerse en la imaginación colectiva como un elemento esencial de nuestra tradición cultural. Su lectura y conocimiento resultan, pues, indispensables como punto de partida de cualquier actuación, tanto en el terreno de la protección como en el de la promoción de los lugares que formen parte del itinerario.

Este proyecto, de llevarse adecuadamente a cabo, puede además constituir un eficaz instrumento de vertebración cultural y social entre la España del interior y la España mediterránea. En consecuencia, la Administración General del Estado debería apoyar su puesta en práctica, a través de los órganos competentes en materia de cultura, turismo y medio ambiente. 